\title{
The Effects of Reuse Marble Waste on Hollow Concrete Blocks in Constructions
}

\author{
Prof.Dr. Osama Ahmad Ibrahim Massoud ${ }^{1}$, Dr. Dina Mahmoud Sadek ${ }^{2}$, Dr. Mohammed \\ Ibrahim Mohammed Abdel Hady ${ }^{3}$, Mahmoud Mohamed Abd Elrazike ${ }^{4}$, Khadiga Elsayed \\ Ahmed Shakra ${ }^{5}$ \\ 1 - Professor of Architecture Eng. Dept. faculty of Eng., Suez University, Cairo, Egypt. \\ 2- Associate Professor, Building Materials Research and Quality Control Institute, Housing and \\ Building National Research Center, Dokki, Giz, Cairo, Egypt \\ 3- Lecturer, Civil and Architectural Constructions Dept. faculty of Industrial Education, Suez \\ University, Cairo, Egypt. \\ 4- Lecturer, Housing and Building National Research Center, Dokki, Giz, Cairo, Egypt. \\ 5- Lecturer assistant Architectural Constructions Dept. faculty of Industrial Education, Beni Suef \\ University, Cairo, Egypt.
}

\begin{abstract}
:
Nowadays, we are facing with the high consumption of raw materials by the construction sector, results in chronic shortage of natural building materials and the associated environmental, Building materials manufacturing is usually accompanied by wastes as by products such as marble waste, which adversely affects the surrounding environment from healthy side and may affect the geometric properties of the soil. Recycling of marble wastes has actually environmental, economic and technical benefits.

In Egypt, the studies to utilize the marble wastes are an important issue because a large amount of this waste has been throwing to the public places and in illegal places. Mentioned several studies for some researchers have proposed reutilizing this waste in building elements, such as concrete or paving block or bricks. It is possible to find a lot of researches in mechanical and physical properties while little effort has been made to characterize recycled marble waste in hollow concrete blocks for their thermal properties.

The aim of this study was to characterize and study influence of marble waste as partial replacement material for coarse aggregate, sand and cement in the hollow concrete block thermal conductivity in order to provide subsidies for a building's thermal performance analysis.
\end{abstract}


The simulation results focused on the evaluating the thermal performance of building as an example of residential agglomerations, this model for house were constructed using four types from hollow concrete block of materials different.

The results indicated that the concrete blocks overall thermal conductivity in the solid region was within the intervals of $0.93,1.34,1.03$ and $1.36 \mathrm{~W} / \mathrm{m} . \mathrm{K}$ respectively.

Keywords: thermal performance, heat transfer; Energy consumption, thermal conductivity, cost, Simulation software.

\section{Introduction}

There is a high tenderly towards recycling of industrial waste specially the marble waste. Marble is one of the common natural building materials that are used in old ages because of its aesthetic properties and homogeneity. In recent years, the demand for the way of marble has increased due to the progress in construction industry, and the population increasing.

Shaq Al-Thoaban at South East Cairo, Egypt, is considered one of the largest marble manufacturing areas because it contains 500 large projects and about 300 workshops, which made Egypt, ranked the $4^{\text {th }}$ in the marble world market and the $7^{\text {th }}$ in the world in the production of stones, (Shaq Al-Thoaban) area produces around 800, 000 tons of wastes per year (Hamza et al., 2011).

The previous studies reported that the use of marble waste as replacement of the building elements (cement, sand and aggregate) could improve the phsicomechanical properties of the elements.

Corinaldesi et al. (2010) and Rodrigues et al. (2015) stated that, the mechanical properties of concrete have enhanced where replaced by $10 \%$ of marble waste.

Ergun (2011) and Rana et al. (2015) stated that the use of 5\% of marble powder and $10 \%$ marble slurry as replacement of cement increased the compressive strength of concrete. Aliabdo et al. (2014) reported that, the replacement of sand by $15 \%$ of marble powder is better for concrete strength than replacing cement.

Ahmed O. Mashaly et al. (2016) found that replacing of a cement substitute in cement and concrete production up to $40 \%$ with marble sludge. The results showed that using up to $20 \%$ of marble sludge, improved the physical and mechanical properties of concrete products.

The building envelope is usually effect by the environmental conditions (solar radiation, temperature, relative humidity and wind speed), which effect the electrical energy consumption inside the building. The electrical energy consumption of air conditioning systems increases as the thermal conductivity of the opaque part increase. The building envelope represents the main axis (major interface between indoors and outdoors) of all thermal control processes and isolates the internal environment from the external one. In addition affects the comfort sense for occupants and heating/cooling loads of internal in the building. Simulation software (design builder) was used to calculate the electrical energy consumption for the case study that was a residential building for which 4 type of blocks were applied and the cost of each block was compared with the local cost. 
The hollow concrete blocks is the most common building materials used, where its annual production reaches about 40 million $\mathrm{m}^{3}$ there are two types of hollow concrete blocks, the first has one cavity and the other has two cavities Y.H. Ye, et al, (2005), Koski, J.A., (1992).

The literature survey showed that, the thermal resistance of the block increase as the number of cavities increase which contributes in improving the energy efficiency of the building while the mechanical properties at the same time S.O. Adepo et al, (2005). The hollow concrete blocks help to save energy and reduce the use of raw materials, which in turn reduces the environmental impact Navaratnarajah et al, (2014).

\section{The Research Methodology}

This study is consisting of five stages:

1. A Literature review has been conducted; the purpose of this review was to impact the properties of marble wastes on the properties of hollow concrete blocks, the bricks, properties of fresh and hardened concrete and other productions.

2. The experimental work of this study was carried out through four phase:

- The first phase, sampling of marble wastes then transport of samples to the place of implementation of the test and production.

- The second phase, the selection of the materials was carried out and the physical, mechanical and chemical characteristics of these materials were evaluated and production of concrete block mixtures with different contributions variables such the percentage of replacement rations of marble wastes

- The third phase, Investigate of the properties of hollow concrete block units containing marble wastes and comparison with normal blocks such as the mechanical properties.

- The fourth phase, Investigate of the properties of hollow concrete block units containing marble wastes and comparison with normal blocks such as the physical properties.

3. Typical residential building has been selected as case study for modeling of thermal condition and evaluation and testing of marble wastes as additive to concrete blocks mixtures for architectural conservation.

4. Using thermal simulation tools to optimize building performance for the evaluation of building thermal simulation tools based on specifications.

\section{Experimental Procedure}

\subsection{Materials}

The study specimens used in this study were prepared from available local materials. 
The mixed materials were derived from the combination of numerous components are it crushed stone, Natural sand, ordinary Portland cement (OPC), water and marble waste as (coarse, fine, and marble powder) from Shaq AlThu ban industrial group. The used ordinary Portland Cement (OPC) CEM I 42.5 N. produced by ASEC Minya cement company. Fine aggregates were used in this study it are natural siliceous sand. Rounded and clean fine aggregate with size 0.15 to $5 \mathrm{~mm}$ was used. The coarse aggregates used in this research were natural crushed stone aggregate passed from $14 \mathrm{~mm}$ sieve and retained on $4.75 \mathrm{~mm}$ sieve. Coarse marble passed from $14 \mathrm{~mm}$ sieve and retained on $4.75 \mathrm{~mm}$ sieve. Fine marble passed from $4.75 \mathrm{~mm}$ sieve. Marble powder is a solid waste material was used in study, which was obtained through the production process of marble can be used in this study as a filler material in cement while preparing hollow concrete block as shown in Figure (1). Its chemical analysis and physical properties is given in table (1). Water should be clean and free from harmful materials.

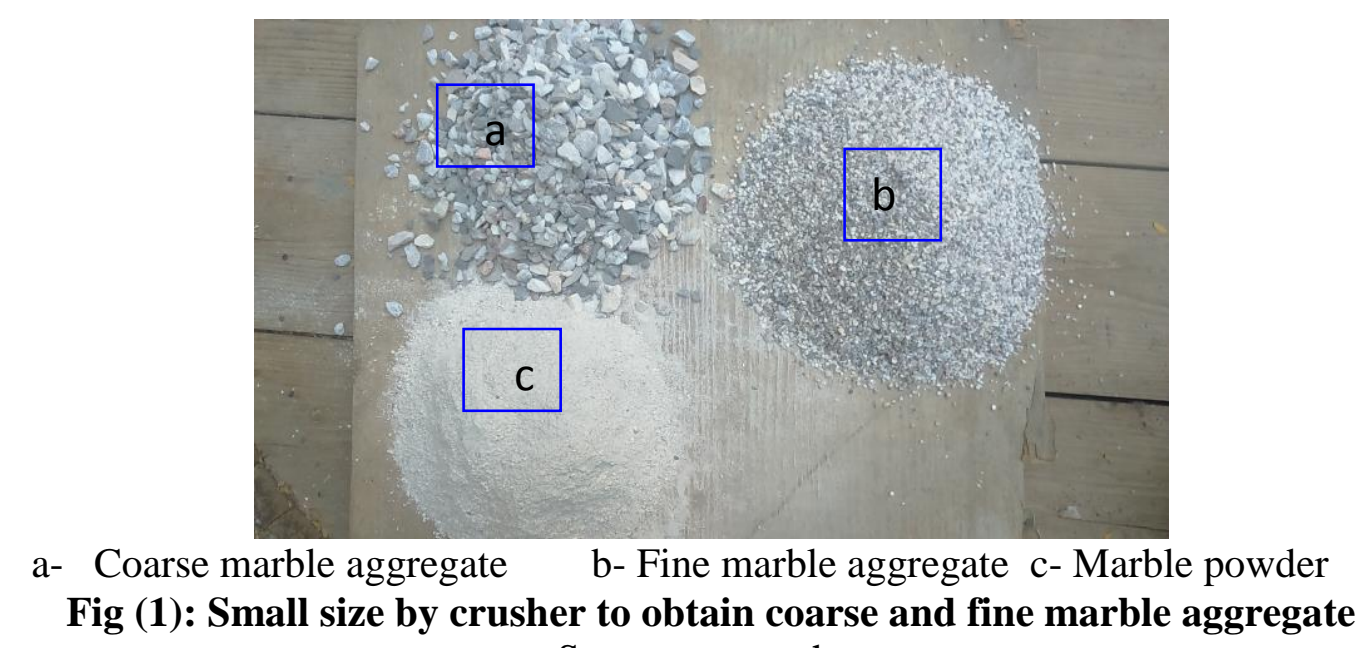

Source: researcher

\subsection{Methods (Blocks Manufacturing):}

The experimental program includes studying the effect of recycling waste marble as replacement materials of aggregate and / or cement in hollow concrete blocks. A total of four concrete mixes were cement content of $200 \mathrm{~kg} / \mathrm{m}^{3}$ and sand to total aggregate ratio of $40 \%$ the control mix $\left(\operatorname{mix}_{1}\right)$ included Portland cement and natural aggregates, while the other mixes of concrete blocks including different sizes of marble wastes (fine marble aggregate, coarse marble aggregate and marble powder) used as replacement of natural materials. Where $\left(\operatorname{mix}_{2}\right)$ incorporated coarse marble wastes passing from $14 \mathrm{~mm}$ sieve replacing $100 \%$ of coarse aggregate. Tow mixes incorporated a combination of more than one type of marble waste in each mix; where $\left(\operatorname{mix}_{3}\right)$ incorporated fine marble waste replacing $50 \%$ of sand and coarse marble waste replacing $100 \%$ of coarse aggregate, while $\left(\mathrm{mix}_{4}\right)$ incorporated coarse marble waste replacing $100 \%$ of coarse aggregate and marble powder replacing $30 \%$ of cement. Table (2) represents the proportions of mixes (by wt.) for mixes. 
The mixes were mixed in a concrete mixer with a capacity of about 250 liters. In the first step of the mixing, coarse and fine aggregates were first mixed in the dry state until the mixture became homogenous. The second step consisted of adding all binding materials (cement, and marble powder) were added to the dry mixture and mixing was continued until the mixture became homogenous. Finally, mixing water was added to the rotating mixer and mixing was continued to assure complete homogeneity. Then hollow concrete blocks of $39 \times 20 \times 20 \mathrm{~cm}$ molds were pressed using a hydraulic press. Figures (2) show the production process of hollow concrete blocks and the casting process. The curing process was done by sprinkling water for 28 days.

Table (1): Chemical analysis and physical properties of marble powder

\begin{tabular}{|c|c|}
\hline Compound & Oxides Contents (\%) \\
\hline Silicon Oxide $\mathbf{S i O}_{\mathbf{2}}$ & 2.34 \\
\hline Aluminum Oxide $\mathbf{A l}_{\mathbf{2}} \mathbf{O}_{\mathbf{3}}$ & 0.32 \\
\hline Ferric Oxide $\mathbf{F e}_{\mathbf{2}} \mathbf{O}_{\mathbf{3}}$ & 0.23 \\
\hline Calcium Oxide $\mathbf{C a O}$ & 55.5 \\
\hline Magnesium Oxide $\mathbf{M g O}$ & 1.07 \\
\hline Sodium Oxide $\mathbf{N a}_{\mathbf{2}} \mathbf{O}$ & 0.12 \\
\hline Potassium Oxide $\mathbf{K}_{\mathbf{2}} \mathbf{O}$ & 0.05 \\
\hline $\mathbf{T i O}_{\mathbf{2}}$ & 0.05 \\
\hline $\mathbf{P}_{\mathbf{2}} \mathbf{O}_{\mathbf{5}}$ & 0.03 \\
\hline $\mathbf{S O}_{\mathbf{3}}$ & 0.29 \\
\hline Loss on Ignition (L.O.I) & 40.10 \\
\hline TOTAL & 99.90 \\
\hline
\end{tabular}

According to ASTM C114-15

Table (2): Represents the proportions of mixes (by wt.) for mixes.

\begin{tabular}{|c|c|c|c|c|c|c|c|}
\hline \multirow[t]{3}{*}{ Mix } & \multicolumn{7}{|c|}{ Ingredients } \\
\hline & \multirow[t]{2}{*}{ Cement } & \multicolumn{2}{|c|}{ Natural aggregate } & \multirow[t]{2}{*}{ Water } & \multicolumn{3}{|c|}{ Waste marble } \\
\hline & & Sand & Dolomite & & $\begin{array}{c}\text { Fine } \\
\text { FA }\end{array}$ & $\begin{array}{c}\text { Coarse } \\
\text { CA }\end{array}$ & $\begin{array}{c}\text { Powder } \\
\text { MP }\end{array}$ \\
\hline Mix $_{1}$ & 200 & 813 & 1219 & 88 & - & - & - \\
\hline $\operatorname{Mix}_{2}$ & 200 & 813 & - & 84.00 & - & 1219 & - \\
\hline Mix $_{3}$ & 200 & 414 & - & 83.50 & 414 & 1219 & - \\
\hline $\operatorname{Mix}_{4}$ & 140 & 813 & - & 84.20 & - & 1219 & 60 \\
\hline
\end{tabular}
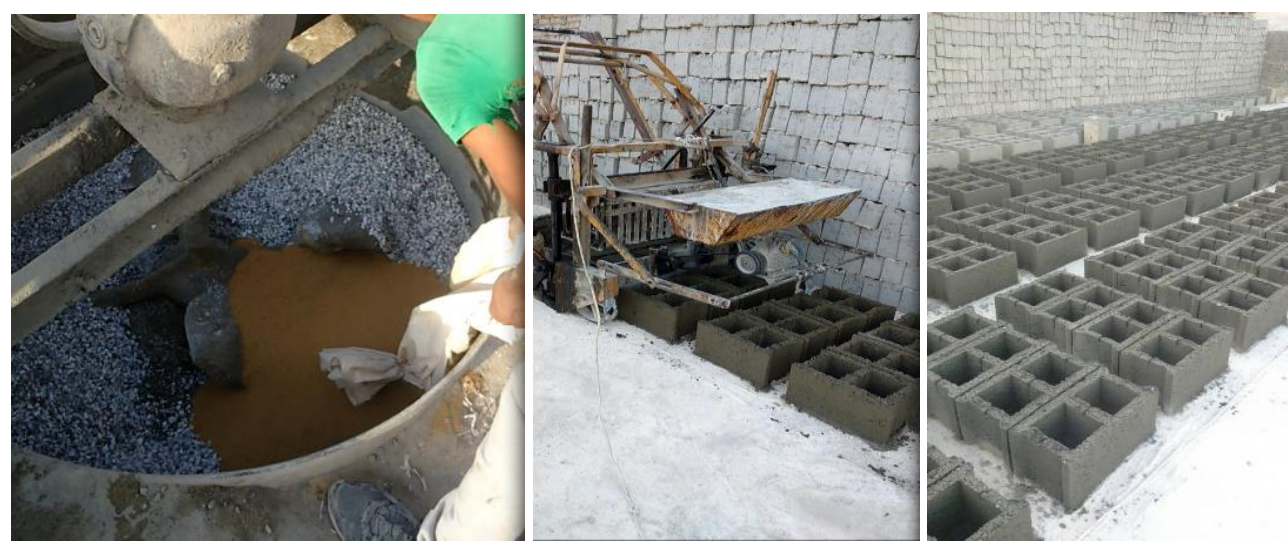

Fig (2) show the production process of hollow concrete blocks.

Source: researcher 


\section{Testing of hollow concrete blocks}

Hollow concrete blocks were tested for the determination of compressive strength, and thermal conductivity.

\subsection{Compressive strength}

Compressive strength test was carried out according to The Egyptian Standard Specifications (ESS) 1292-1 and 1292-2 and ASTM C140 [16-18]. Five hollow concrete blocks were tested in compression at 7, 28, 56 and 180 days. Finger (3) shows compressive test.

The compressive strength "fc" was calculated using the formula:

$$
\mathrm{fc}=\frac{P_{\mathrm{c}}}{\mathrm{A}}
$$

Pc maximum compressive load $(\mathrm{N})$,

A is the cross-section area of the specimen

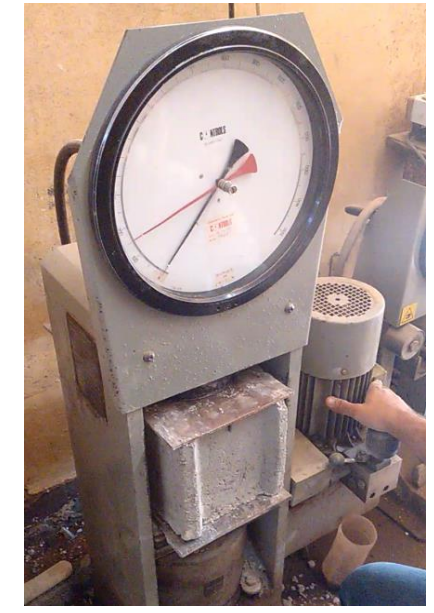

Fig (3): Compressive strength test

Source: researcher $\left(\mathrm{mm}^{2}\right)$.

\subsection{Thermal Conductivity}

Thermal conductivity $(\mathrm{K})$ is the property of a material's ability to conduct heat. Heat transfer by conduction involves transfer of energy within a material without any motion of the material as a whole. The calculation is derived from amount of the heat flow per square area absorbed by sample after switching instrument's plate's temperature set points from one after reaching thermal equilibrium condition to another until reaching new thermal equilibrium condition. Accurate experimental corrections for heat absorbed by the heat flow meters and for edge heat losses are applied to get the best accuracy.

Requires testing of two identical samples typically $30 \times 30 \times 5 \mathrm{~cm}$, were cast for the determination of thermal conductivity at test ages of 28 days. To verify the suitability and the accuracy of the equipment used for measuring the thermal conductivity based on the hot wire method, Figure (4) shown a schematic outline of the structure of the test equipment for method. Flat-parallel sample is sandwiched between two isothermal plates. Each plate has a temperature sensor and a heat flow meter transducer converting the heat flow into electric voltage. 
This test can be described as follows; the sample is placed between two plates, the first one is a flat electrical heating plate and the other one is flat

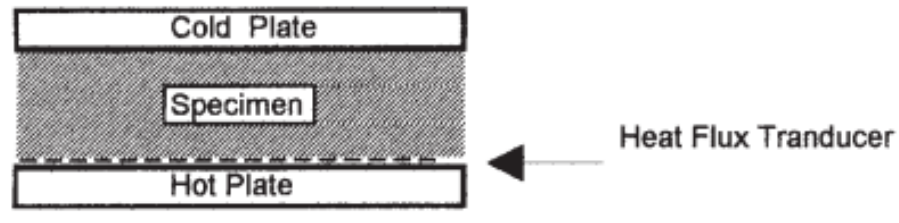

Fig (4): schematic outline of the structure of the test equipment for the method [source: ASTM C518-02e1]. electrical cooling plate. Figure

(5) shows the details of thermal conductivity apparatus used in this study. All the information about the sample is recorded and the test started. It may be 6 to 8 hours till the condition of steady state reach. Through this time the software store the temperature of the hot plate and the cooled plate and the heat flux through the samples. Finally the thermal conductivity was calculated using the following Equation;

$$
\begin{gathered}
\mathrm{K}=\mathrm{Q} . \mathrm{L} \\
\text { A. } \Delta \mathrm{T}
\end{gathered}
$$

Where

"Q" is the heat load on the sample [W].

" $L "$ is the length of the sample that the heat flow travels through [m].

"A" is the cross sectional area that the heat is applied to $\left[\mathrm{m}^{2}\right]$.

And " $\Delta \mathrm{T}$ " is the temperature different across the sample top and bottom surface.
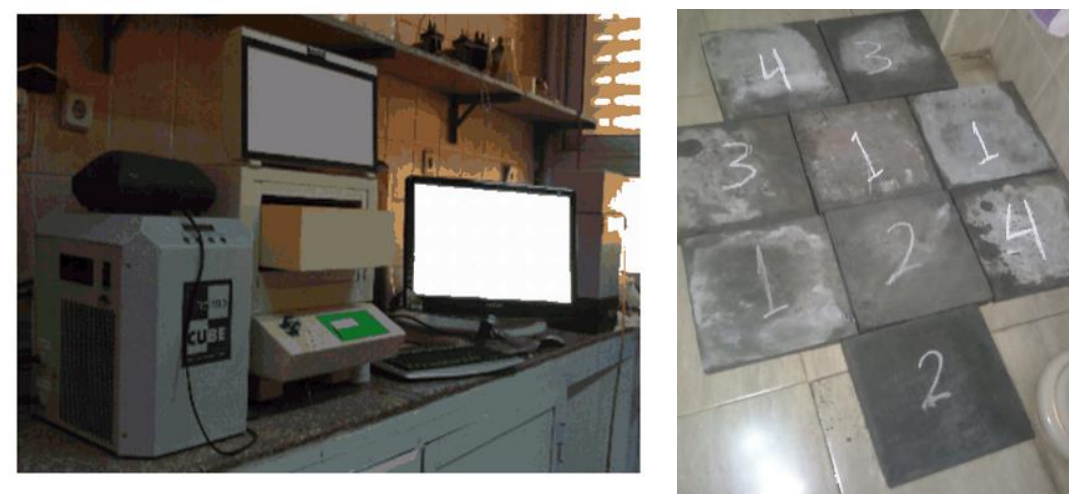

Fig (5): measurement of sample testing, system configurations and applications heat flow. Source: researcher

\section{Thermal Simulation}

The desire for search of safe and structural materials keeping in view the economy and energy of whole structure. Therefore the recycling of wastes from other industries will increase the eco efficiency of hollow concrete blocks.

Experimental studies on thermal performance of building walls representing the different types of existing systems to compare their thermal performance.

This study describes potential for using thermal simulation tools to optimize building performance. After (reviewing current trends) in thermal simulation, it outlines major criteria for the evaluation of building thermal simulation tools based on specifications. 


\subsection{Thermal modeling tool}

There are several computer tools for building thermal modeling with several simulation methods. The evaluation of the thermal performance of the hollow concrete blocks with low emissivity treatment on the surface of the cavities was carried out using the Design Builder Software [19] is a complete building design and environmental analysis tool that include the variety large of simulation and analysis functions. It resembles a style and technique 3D modeling interface with extensive solar, thermal, acoustic, lighting and cost analysis function. Figure (8) shown in steps of the thermal simulation model.

Measurement of thermal conductivity of building blocks which are composite in as the nature. Test building for comparison of different types of building walls was conceptualized. Since the nature of the construction, location and the external conditions are similar in nature for the different types of walls; their thermal performance.

To simulate the heat exchange inside the cavities, a simplified and standardized method using equivalent conductivity was used.

\section{The main assumptions considered for the simulation process are:}

- Two dimensional model;

- Steady state condition;

- Equivalent conductivity (radiative and convective part);

- All thermo physical properties kept constant;

- Emissivity values of the emitting and receiving surfaces are equal $(\varepsilon 1=\varepsilon 2)$;

- Thermal resistance of the voids calculated according to B.3 of EN ISO 6946:1996 [20].

- Thermal resistance of the holes with non-rectangular shape is assumed equal to a rectangular hole with the same area and the same dimensional ratio $(\mathrm{d} / \mathrm{b})[20]$

\subsection{Modeling}

This study investigates simulation analysis which aims at improving the thermal performance of buildings through variations of external walls in Egypt. The finding of this paper presents preliminary thermal analysis done for an air conditioned standard building. The study focused on the thermal performance assessment of the building's local construction wall materials and the analysis has been carried out using dynamic thermal simulations using the hourly weather data of Cairo and setting climatic and treatments for the future extension zone buildings of New Capital Cairo.

The simulations in this study was carried out in two consecutive stages, the first stage addressed the air temperature and energy usage on a year round to define the peak day and the worst orientation among the main four orientations and 
results focused on the peak day occupancy time and the worst orientation performance of the building. The second stage investigates the effects of using marble wastes in industry of hollow concrete blocks and potential thermal impacts of internal courtyard. Results were analyzed and compared in the four stages when using marble wastes.

A typical residential buildings space was selected for assessment as in figure (6) to (7), wall construction materials were selected according to survey done for façade materials of residential buildings in New Capital Cairo in Cairo.

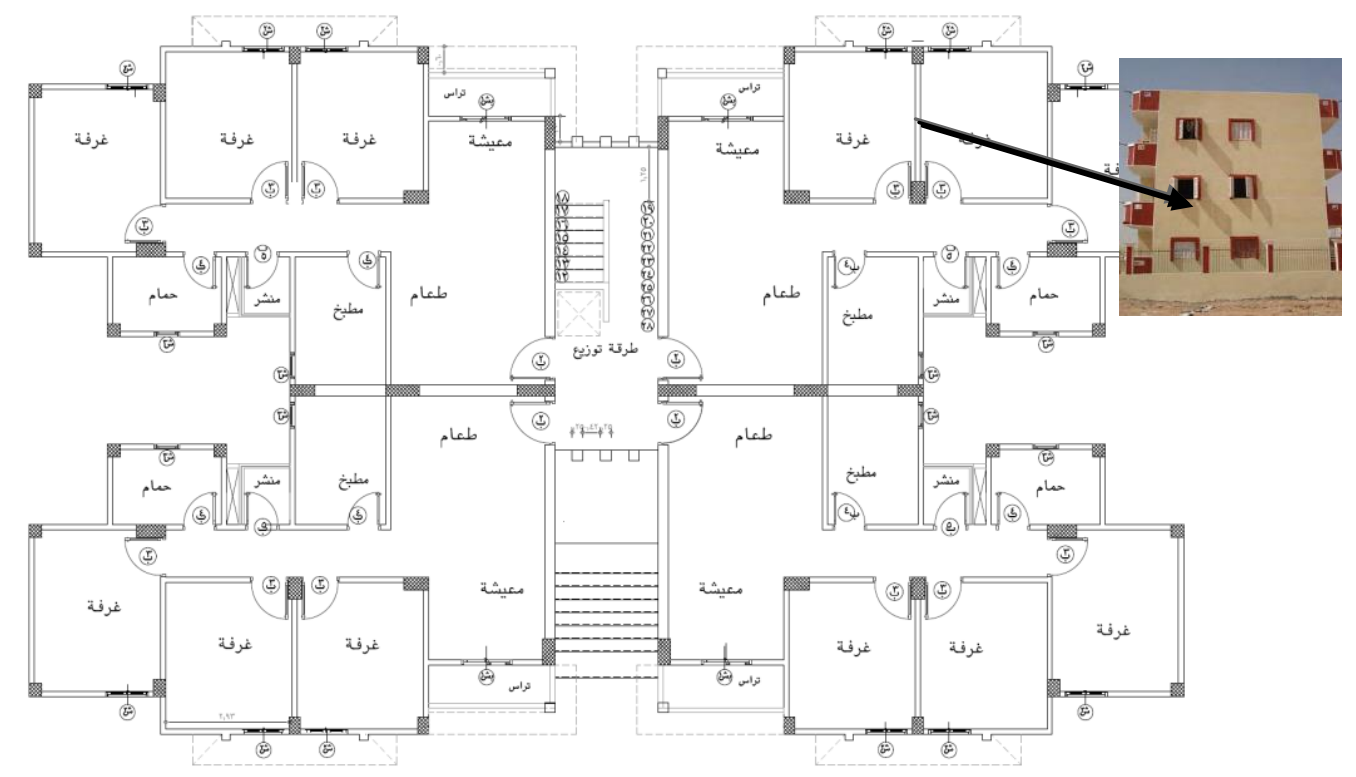

Fig (6): Case study residential building plan.

\subsection{Envelop properties}

A case study house has been selected for modeling and evaluation of thermal condition in fig (7). The house consists of;

House: This house is for bedrooms, the kitchen, bathroom and reception.

Material: for Design Builder Software model materials for the building are either chosen from Design Builder Software library or created from user library table (3). Construction materials were chosen based on the façade and roof materials, materials were concrete hollow blocks with utilization replacement percentage by marble wastes. 


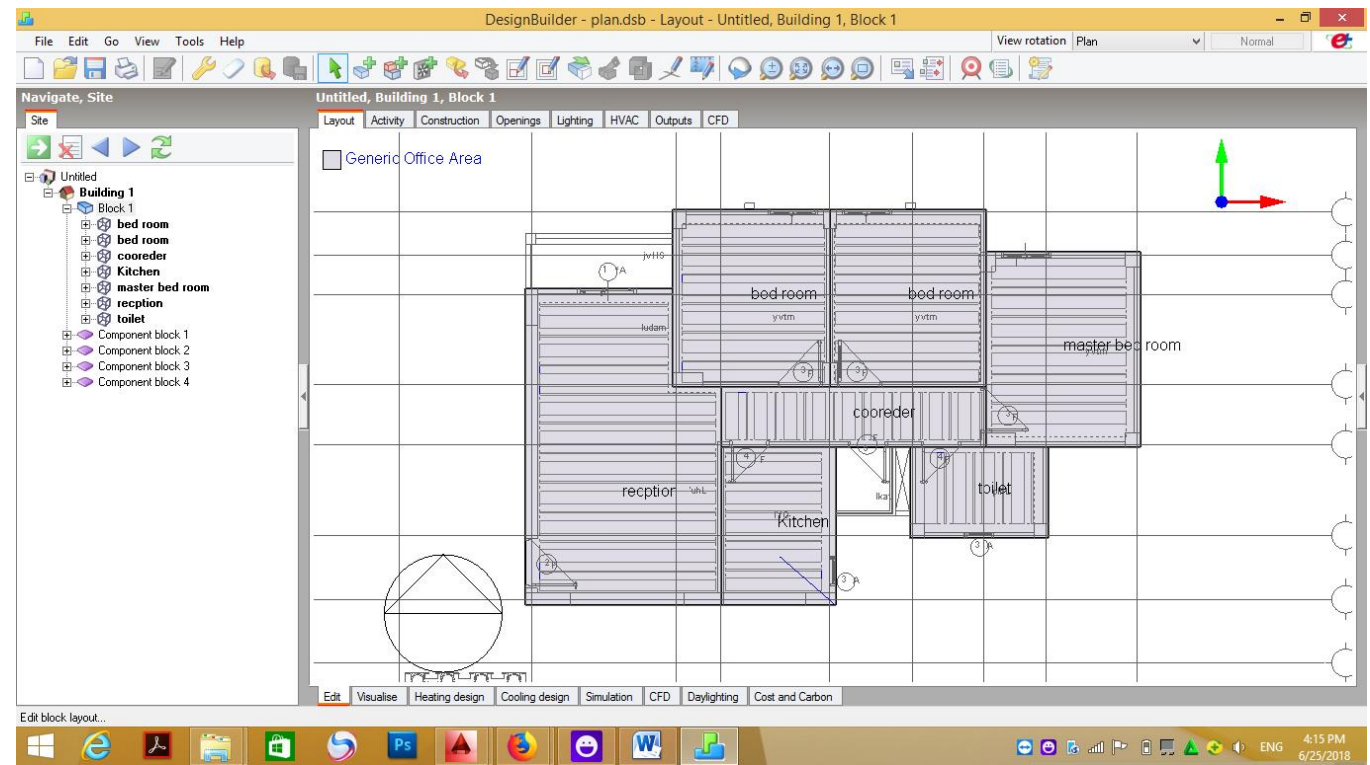

Drawing one apartment from building wherein attaching walls for neighboring to making of adiabatic even not to be influenced on calorie load in apartment interior Fig $\left(7_{\mathrm{A}}\right)$ : Case study apartment plan

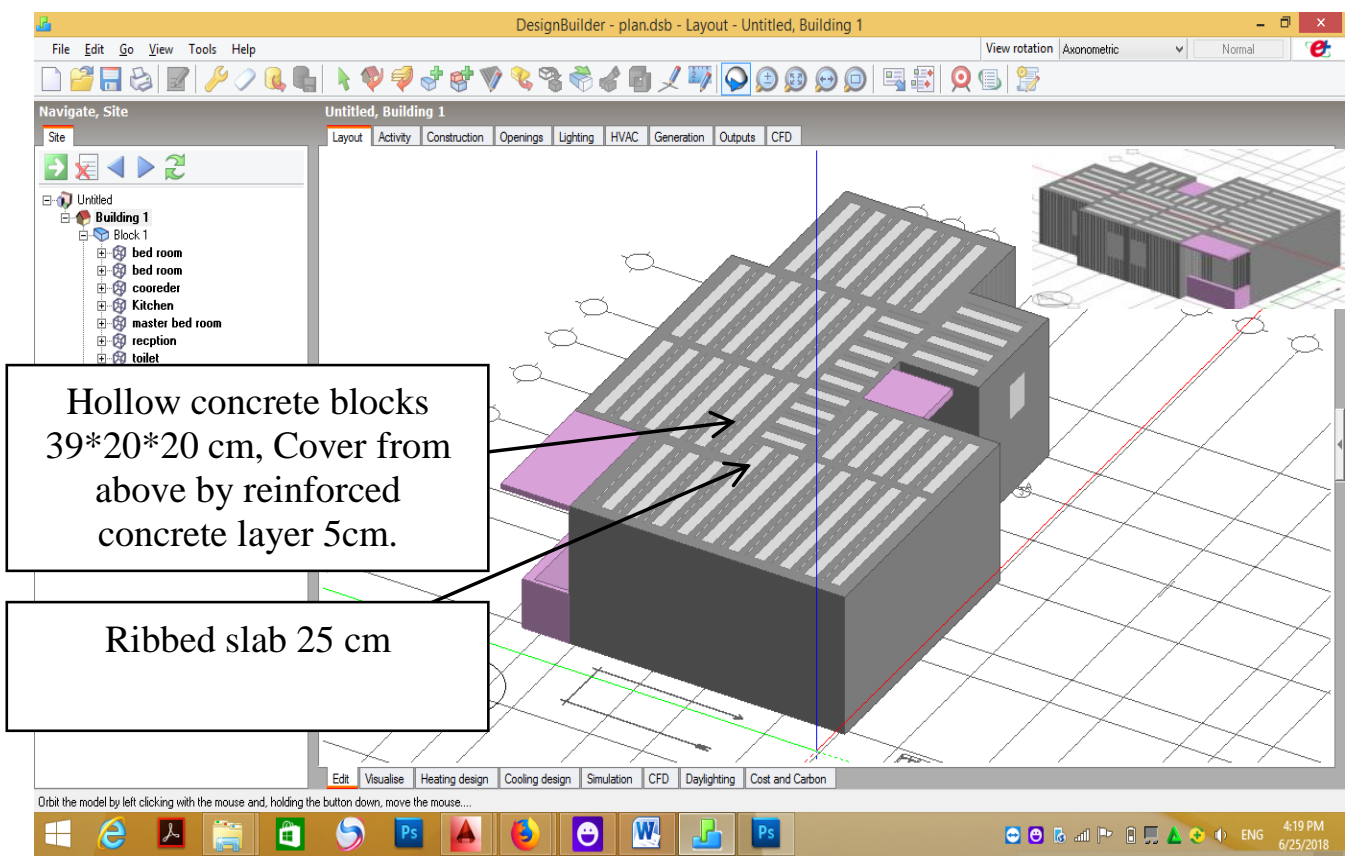

Fig $\left(\mathbf{7}_{\mathbf{B}}\right)$ : Perspective shot for case study

Fig (7): Perspective for case study. Source: researcher

Table (3): Material properties for the case study building.

\begin{tabular}{|c|c|c|c|}
\hline & Material description & $\begin{array}{l}\text { U-Value } \\
\left(\mathbf{w} / \mathbf{m}^{2} \mathbf{k}\right)\end{array}$ & R-value $\left(w / m^{2} k\right)$ \\
\hline Roof $_{1}$ & $100 \mathrm{~mm}$ thick suspended concrete floor & 5.29 & 0.181 \\
\hline
\end{tabular}




\begin{tabular}{|c|c|c|c|}
\hline Roof $_{2}$ & 2.100 & 0.476 \\
\hline Wall $_{1}$ & $200 * 125 * 60 \mathrm{~mm}$ Brick concrete solid & 2.597 & 0.385 \\
\hline Wall & $390 * 200 * 200 \mathrm{~mm}$ hollow concrete block & 2.200 & 0.455 \\
\hline Door & $40 \mathrm{~mm}$ thick hollow core plywood door & & \\
\hline Window & single glazed $6 \mathrm{~mm}$ with oriel & 6.121 & $0.65-40$ \\
\hline
\end{tabular}

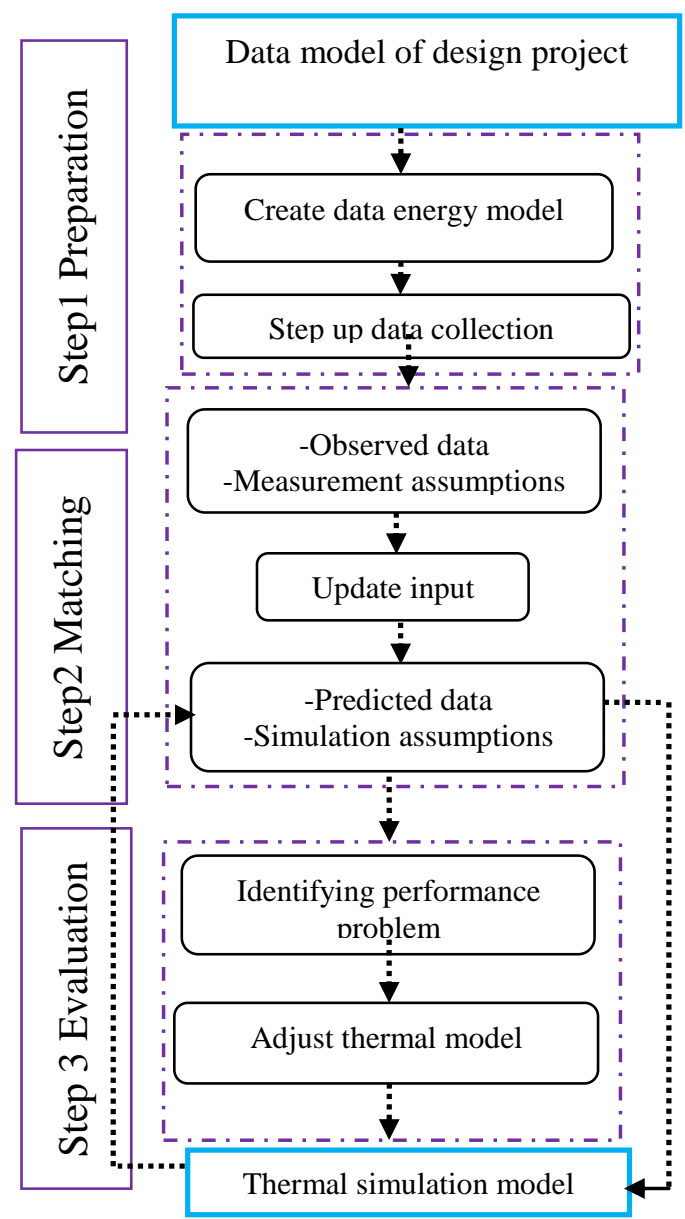

Fig (8): Work flow to produce and steps of the thermal simulation model

Source: researcher

\section{Results and discussion \\ 6.1 Compressive strength}

The compressive strength of hollow concrete blocks is of crucial importance for design and safety assessment purposes. Table (4) shows the effect of marble waste size (coarse marble, fine marble and marble powder) on the 7, 28, 56 and 180 days compressive strength of hollow concrete blocks. It can be observed that 
in general, the compressive strength values for hollow concrete blocks containing coarse marble aggregate are higher than those for blocks containing fine marble as recycled aggregate, regardless of replacement percentage of conventional aggregates (sand or dolomite). On the other hand, in case of using marble powder as a replacement of cement, the compressive strength values for hollow concrete blocks containing marble powder were found to be lower than those of blocks containing the coarse or fine marble aggregate, regardless of replacement percentage of conventional materials. Hence, from the technical point of view, it is perfected to be marble waste as coarse aggregate than being used as fine aggregate and marble powder of cement.

Compared with control block, the addition of coarse marble at $100 \%$ resulted in a concrete strength decrease of $3.22 \%$ at 28 day, while using of marble waste at (50\% fine marble FA $+100 \%$ coarse marble $\mathrm{CA})$ reduced the block strength by $16.1 \%$, while the decrease by using $(100 \% \mathrm{CA}+30 \%$ marble powder MP $)$ was $21.3 \%$ in the same ages. These results indicate that a higher percentage of replacement resulted in a lower compressive strength.

\section{Table (4) shows comparing between the effects of the different sizes of marble} waste.

The increasing of Portland cement replacement with marble sludge addition lead to decreasing in compressive strength resulting in potential reduction in the cementing materials causing a dilution of $\mathrm{C}_{2} \mathrm{~S}$ and $\mathrm{C}_{3} \mathrm{~S}$ which are the main constituents and strength providers of cement Bonavetti et al., (2000); Güneyisi et al., (2009); Ergun, (2011) due to the higher water demands of concrete

\begin{tabular}{|c|c|c|c|c|}
\hline \multirow{2}{*}{ Mix } & \multicolumn{4}{|c|}{ Compressive strength } \\
\cline { 2 - 5 } & $\mathbf{7}$ days & $\mathbf{2 8}$ days & $\mathbf{5 6}$ days & $\mathbf{1 8 0}$ days \\
\hline $\mathbf{0 \%}$ & 110 & 155 & 170 & 195 \\
\hline $\mathbf{1 0 0 \%} \mathbf{C A}$ & 106 & 150 & 159 & 192 \\
\hline $\mathbf{5 0 \%} \mathbf{F A + 1 0 0 \%} \mathbf{C A}$ & 98 & 130 & 154 & 164 \\
\hline $\mathbf{1 0 0 \%} \mathbf{C A}+\mathbf{3 0 \% M P}$ & 91 & 122 & 149 & 157 \\
\hline
\end{tabular}

mixtures containing higher marble content as a result of their higher specific surface area more than cement.

On the other hand, the pore-filling effect of fine marble powder with providing the suitable nucleus for hydration means increasing in compressive strength. This marble sludge is could be assumed as ultrafine aggregates filling concrete voids Bonavetti et al., (2000); Ergun, (2011) that enhance the properties of the transition zone surrounding aggregate Aliabdo et al., (2014).

Also, the reason of improving compressive strength of concretes by the addition of fines marble are accelerating the hydration of clinker minerals, especially $\mathrm{C}_{3} \mathrm{~S}$ and carboaluminates are formed and they act as nucleation sites for $\mathrm{CH}$ and 
$\mathrm{CeSeH}$ reaction products at early ages, resulting in an improvement in early strength Heikal et al., (2000); Ergun, (2011); Meddah et al., (2014).

Using different types of cement Gencel et al. (2012) investigated the feasibility and effects of using waste marble as aggregate replacement on physical and mechanical properties of concrete paving blocks. They reported that there are indirect relation between marble content and mechanical strength while freezethaw durability and abrasive wear resistance increase. Rana et al. (2015) have shown that to achieving the best performance of concrete properties occur by replacing up to $10 \%$ of cement with marble slurry.

\subsection{Thermal conductivity}

The apparent thermal conductivity of is related to density. Tests of the same density at varying containing material were conducted in accordance with ASTM C 518 steady state thermal transmission properties by means of the (Heat Flow Meter) to determine if a the materials content effect' was present. Table (5) exhibits this consistency of measured conductivity in several samples of at varying material content. For the range of density typically used as hollow concrete blocks there is little or no containing material effect results of measurements at test containing material of 1 to 4 " are representative of the material in use.

Table (5) Exhibits this consistency of measured conductivity in several samples of at varying containing material

\begin{tabular}{|c|c|c|c|c|}
\hline Mix & Samples & $\begin{array}{c}\text { Thicknesses } \\
\text { (cm) }\end{array}$ & Density & $\begin{array}{c}\text { Thermal } \\
\text { conductivity } \\
(\mathrm{W} / \mathrm{m} . \mathbf{K})\end{array}$ \\
\hline Mix 1 & control & 5 & 2189 & 0.93 \\
\hline Mix 2 & 100\% CA (hollow) & 5 & 2187 & 1.34 \\
\hline Mix 3 & $50 \%$ FA+ $100 \%$ CA (hollow) & 5 & 1970 & 1.03 \\
\hline Mix 4 & $100 \% \mathrm{CA}+30 \% \mathrm{P}$ (hollow) & 5 & 1950 & 1.36 \\
\hline
\end{tabular}

\section{- Effect of using different sizes of marble waste}

Table (5) and Figure (9) shows comparing between the effects of the different sizes of marble waste on density and thermal conductivity for choose samples. For mixes were compared with the control hollow concrete blocks made with conventional materials (cement, dolomite and sand). These mixes incorporated ( $100 \%$ coarse marble aggregate $\mathrm{CA}$ ), (50\% fin marble aggregate FA+ $100 \%$ coarse marble aggregate $\mathrm{CA}$ ) and (100\% coarse marble aggregate $\mathrm{CA}+30 \%$ marble powder MP).

It can be found for the figure that mixes containing control showed the lowest thermal conductivity followed by mix containing (50\% FA+100\% CA), the mix containing $(100 \% \mathrm{CA})$ and finally mix containing $(100 \% \mathrm{CA}+30 \% \mathrm{MP})$ showed the highest thermal conductivity. While density found for the figure that mixes containing control was the highest density followed by mix containing $(100 \% \mathrm{CA})$, the mix containing $(50 \% \mathrm{FA}+100 \% \mathrm{CA})$, and finally mix 
containing (100\% CA $+30 \% \mathrm{MP})$ showed the lowest density. Marble powder incorporation had a positive effect on density, shrinkage and plasticity during all stages of the production process, anticipating some modifications in the industrial production line [9].

Panels were tested with three different sizes of marble waste and also different ratios. Control sample were similar in overall thermal performance. The sample $100 \% \mathrm{CA}$ had a $44 \%$ high thermal conductivity than the control sample, while sample $50 \% \mathrm{FA}+100 \% \mathrm{CA}$ had a $10.75 \%$ high thermal conductivity than the control sample, while sample $100 \% \mathrm{CA}+30 \% \mathrm{MP}$ had a $46.24 \%$ high thermal conductivity than the control sample. Therefore, uses the marble wastes to make hollow concrete blocks will influence on the thermal conductivity negative. The lower resistance and conductivity values are justified by the presence of aggregate with a lower density and lower thermal conductivity than the natural aggregate.

This is an expected outcome due to the high specific gravity of waste marble dust and also filler effect of marble dust because it has finer particles than fine sand aggregate. The porosity of the concrete decreased and ultrasonic pulse velocity increased with increasing percentage of marble dust additions.

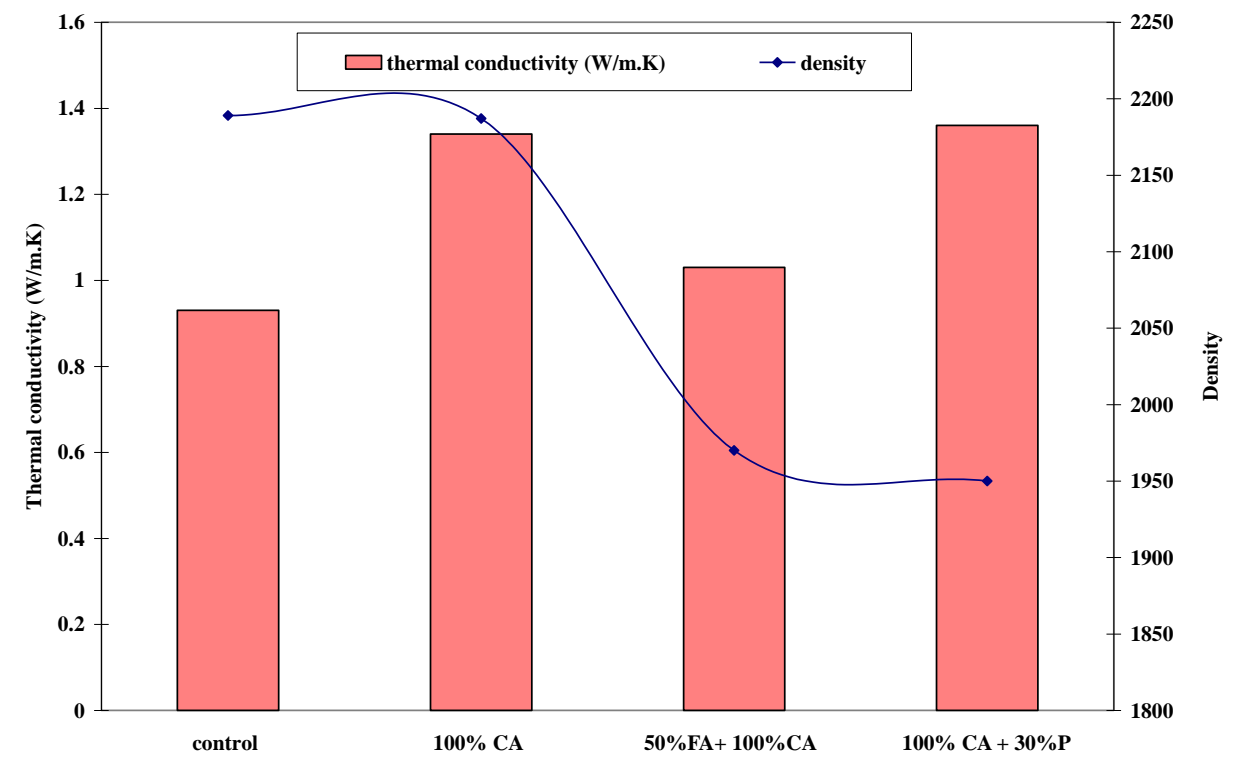

Fig (9): Effect and comparing between the effects of the different sizes of marble waste on density and thermal conductivity. Source: researcher

Figure (10) to Figure (14) shows comparing between the effects of the different sizes of marble waste on thermal conductivity, energy consumption, price and compressive strength for choose samples.

Figure (10) shows the effecting using different sizes of marble waste on the thermal conductivity and energy consumption of hollow concrete blocks using in building. For mixes were compared with the control hollow concrete blocks made with conventional materials (cement, dolomite and sand). These mixes incorporated (100\% coarse marble aggregate CA), (50\% fin marble aggregate 
$\mathrm{FA}+100 \%$ coarse marble aggregate $\mathrm{CA})$ and (100\% coarse marble aggregate $\mathrm{CA}$ $+30 \%$ marble powder MP).

It can be found for the figure that mixes containing control showed the lowest thermal conductivity followed by mix containing (50\% FA+100\% CA), solid cement brick, the mix containing $(100 \% \mathrm{CA})$ and finally mix containing $(100 \%$ $\mathrm{CA}+30 \% \mathrm{MP})$ showed the highest thermal conductivity. While energy consumption found for the figure that mixes containing solid cement brick was the highest energy consumption followed by mix containing $(100 \% \mathrm{CA})$, the mix containing $(100 \% \mathrm{CA}+30 \% \mathrm{MP})$, the mix containing $(50 \% \mathrm{FA}+100 \% \mathrm{CA})$ and finally mix containing control showed the lowest energy consumption.

Hollow concrete blocks for mixes were compared with the control hollow concrete blocks, with (100\%CA), (50\%FA+ 100\%CA) and $(100 \% \mathrm{CA}+$ $30 \% \mathrm{MP}$ ) had $44.09 \%, 10.75 \%$ and $46.24 \%$ to the thermal conductivity respectively, while the energy consumption was $2.13 \%, 0.58 \%$ and $0.83 \%$ respectively.

Figure (11) shows the effecting using different sizes of marble waste on the thermal conductivity and price of hollow concrete blocks using in building. For mixes were cost and compared with the control hollow concrete blocks made with conventional materials (cement, dolomite and sand).

It can be found for the figure that mixes containing control showed the lowest thermal conductivity followed by mix containing (50\% FA+100\% CA), solid cement brick, the mix containing $(100 \% \mathrm{CA})$ and finally mix containing $(100 \%$ $\mathrm{CA}+30 \% \mathrm{MP})$ showed the highest thermal conductivity. While the cost found for the figure that mixes containing solid cement brick was the lowest cost followed by mix containing $(100 \% \mathrm{CA}+30 \% \mathrm{MP})$, the mix containing $(50 \%$ $\mathrm{FA}+100 \% \mathrm{CA})$, the mix containing $(100 \% \mathrm{CA})$ and finally mix containing control showed the highest cost.

The mixes were compared with the control hollow concrete blocks, with $(100 \% \mathrm{CA}),(50 \% \mathrm{FA}+100 \% \mathrm{CA})$ and $(100 \% \mathrm{CA}+30 \% \mathrm{MP})$ had $44.09 \%$, $10.75 \%$ and $46.24 \%$ to the thermal conductivity respectively, while the decrease of price was $19.37 \%, 22.39 \%$ and $27.54 \%$ respectively.

Figure (12) shows the effecting using different sizes of marble waste on the energy consumption and price of hollow concrete blocks using in building. For mixes were cost and compared with the control hollow concrete blocks made with conventional materials (cement, dolomite and sand).

It can be found for the figure that mixes containing solid cement brick showed the highest energy consumption followed by mix containing (100\% CA), the mix containing $(100 \% \mathrm{CA}+30 \% \mathrm{MP})$, the mix containing $(50 \% \mathrm{FA}+100 \% \mathrm{CA})$ and finally mix containing control showed the lowest energy consumption. While the cost found for the figure that mixes containing solid cement brick was the lowest cost followed by mix containing $(100 \% \mathrm{CA}+30 \% \mathrm{MP})$, the mix containing 
$(50 \% \mathrm{FA}+100 \% \mathrm{CA})$, the mix containing (100\% CA) and finally mix containing control showed the highest cost.

The mixes were compared with the control hollow concrete blocks, with $(100 \%$ $\mathrm{CA}),(50 \% \mathrm{FA}+100 \% \mathrm{CA})$ and $(100 \% \mathrm{CA}+30 \% \mathrm{MP})$ had $2.13 \%, 0.58 \%$ and $0.83 \%$ to the energy consumption respectively, while the decrease of price was $19.37 \%, 22.39 \%$ and $27.54 \%$ respectively.

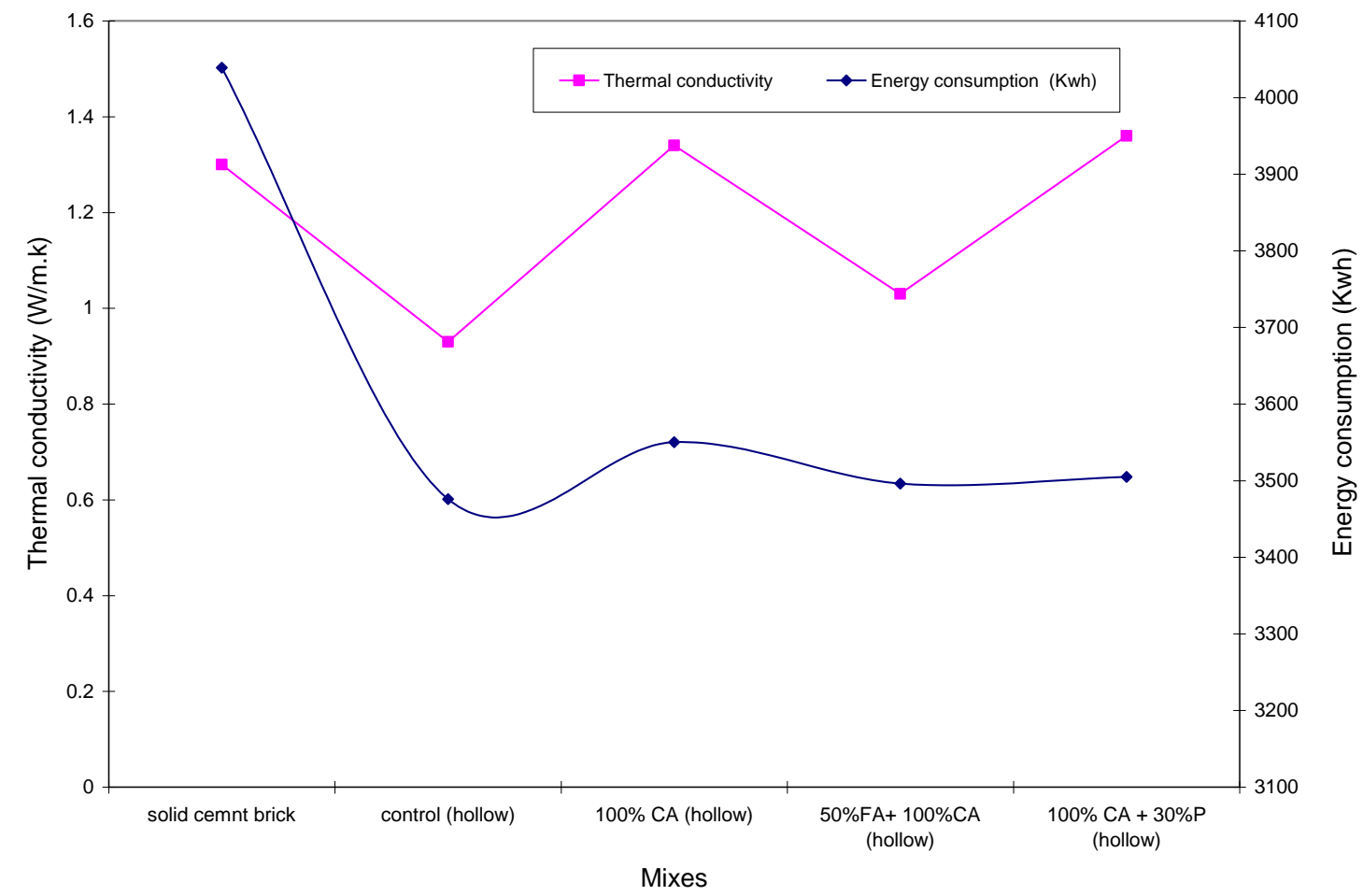

Fig (10): Effect and comparing between the effects of the different sizes of marble waste on Thermal conductivity and Energy consumption. Source: researcher 


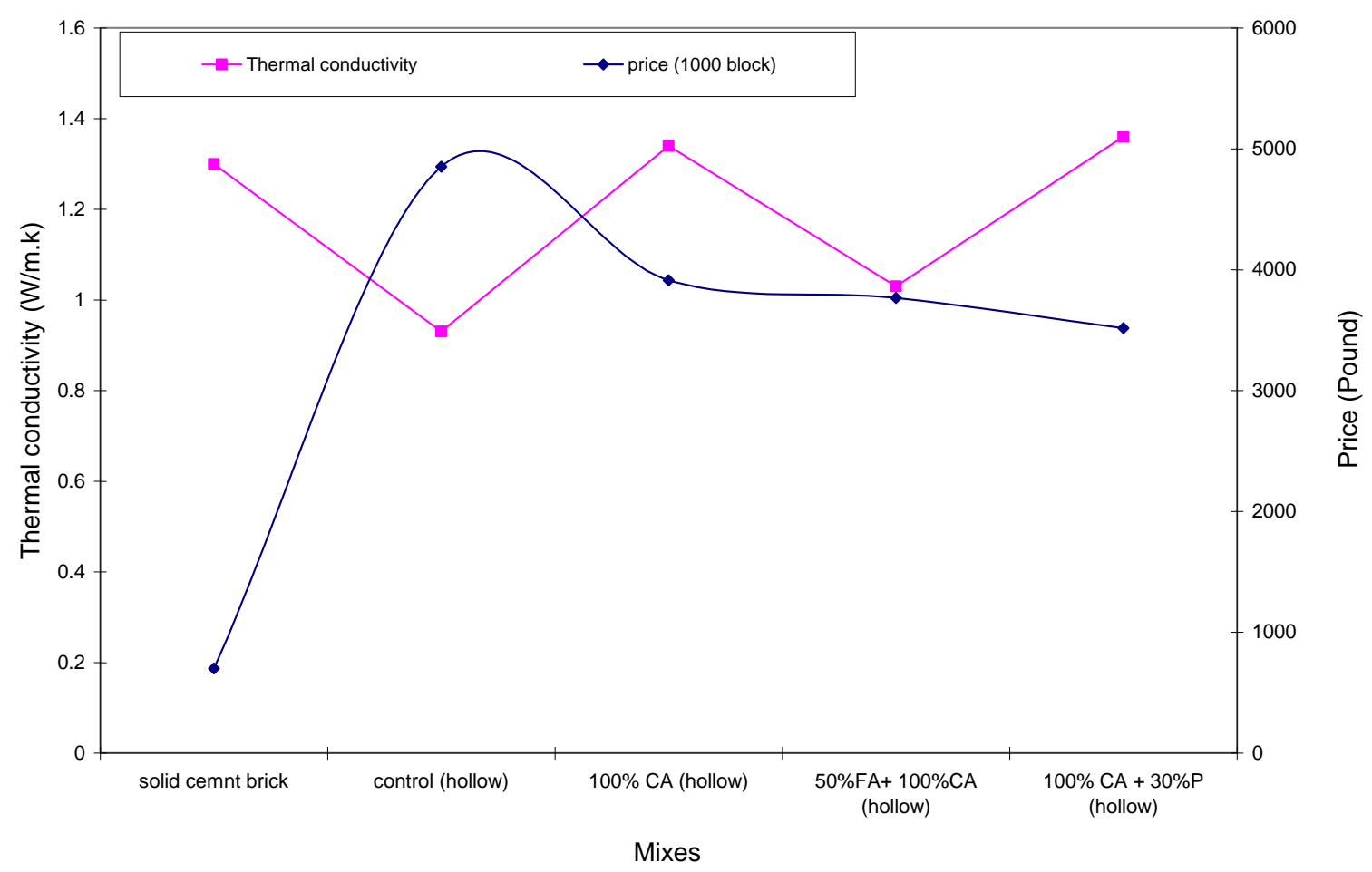

Fig (11): Effect and comparing between the effects of the different sizes of marble waste on Thermal conductivity and price. Source: researcher

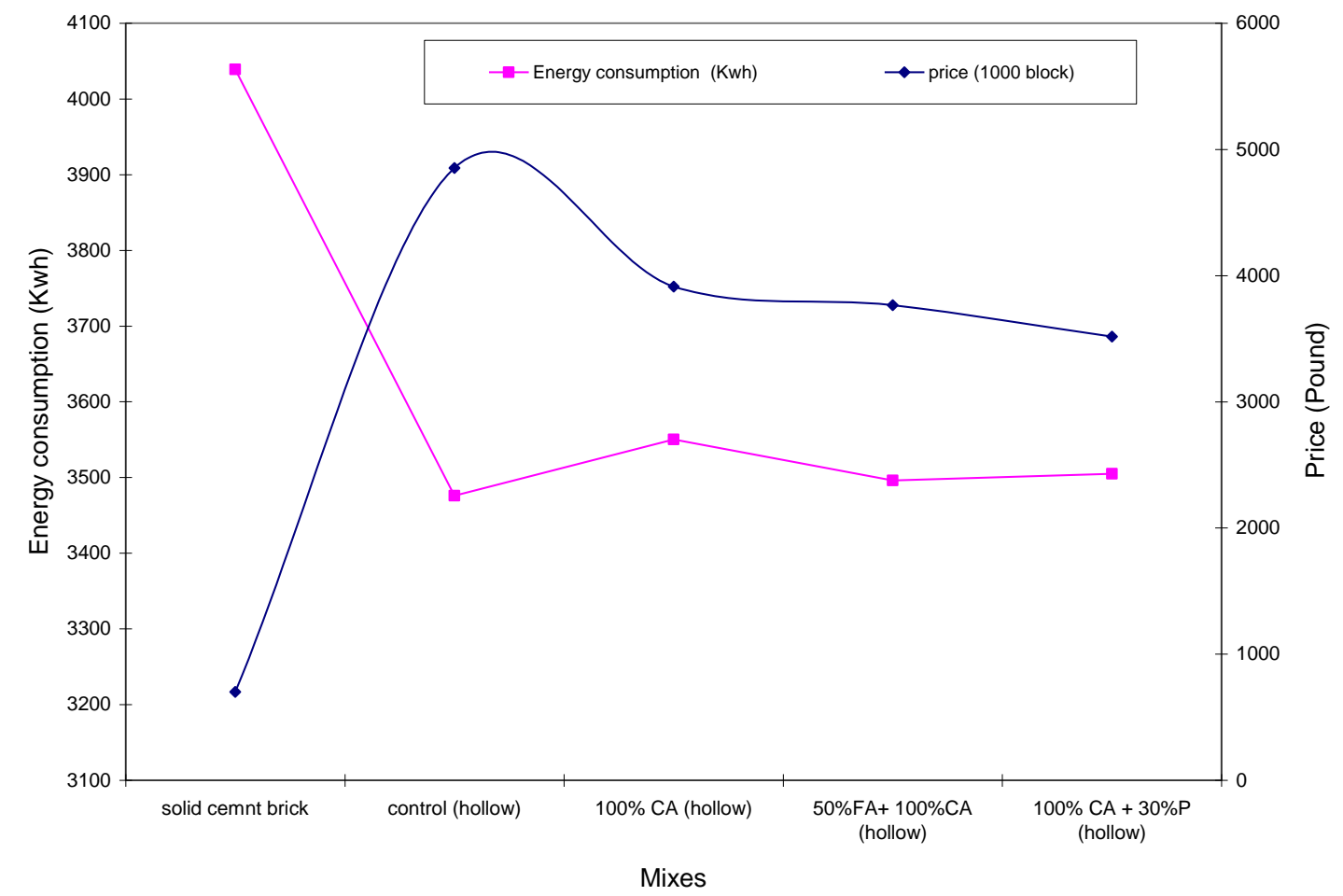

Fig. (12): Effect and comparing between the effects of the different sizes of marble waste on Energy consumption and price. Source: researcher

Figure (13) shows the effecting using different sizes of marble waste on the energy consumption and compressive strength of hollow concrete blocks using in 
building. For mixes were compared with the control hollow concrete blocks made with conventional materials (cement, dolomite and sand).

It can be found for the figure that mixes containing solid cement brick showed the highest energy consumption followed by mix containing (100\% CA), the mix containing $(100 \% \mathrm{CA}+30 \% \mathrm{MP})$, the mix containing $(50 \% \mathrm{FA}+100 \% \mathrm{CA})$ and finally mix containing control showed the lowest energy consumption. While the compressive strength found for the figure that mixes containing control was the highest of compressive strength followed by mix containing $(100 \% \mathrm{CA})$, the mix containing $(50 \% \mathrm{FA}+100 \% \mathrm{CA})$ and finally mix containing control showed the lowest compressive strength $(100 \% \mathrm{CA}+30 \% \mathrm{MP})$.

The mixes were compared with the control hollow concrete blocks, with $(100 \% \mathrm{CA}),(50 \% \mathrm{FA}+100 \% \mathrm{CA})$ and $(100 \% \mathrm{CA}+30 \% \mathrm{MP})$ had $2.13 \%, 0.58 \%$ and $0.83 \%$ to the energy consumption respectively, while the decrease of compressive strength was $3.23 \%, 16.13 \%$ and $21.29 \%$ respectively.

Figure (14) shows the effecting using different sizes of marble waste on the thermal conductivity and compressive strength of hollow concrete blocks using in building. For mixes were compared with the control hollow concrete blocks made with conventional materials (cement, dolomite and sand).

It can be found for the figure that mixes containing control showed the lowest thermal conductivity followed by mix containing (50\% FA+ 100\% CA), solid cement brick, the mix containing $(100 \% \mathrm{CA})$ and finally mix containing $(100 \%$ $\mathrm{CA}+30 \% \mathrm{MP})$ showed the highest thermal conductivity. While the compressive strength found for the figure that mixes containing control was the highest of compressive strength followed by mix containing (100\% CA), the mix containing $(50 \% \mathrm{FA}+100 \% \mathrm{CA})$ and finally mix containing control showed the lowest compressive strength $(100 \% \mathrm{CA}+30 \% \mathrm{MP})$.

The mixes were compared with the control hollow concrete blocks, with $(100 \% \mathrm{CA}),(50 \% \mathrm{FA}+100 \% \mathrm{CA})$ and $(100 \% \mathrm{CA}+30 \% \mathrm{MP})$ had $44.09 \%$, $10.75 \%$ and $46.24 \%$ to the thermal conductivity respectively, while the decrease of compressive strength was $3.23 \%, 16.13 \%$ and $21.29 \%$ respectively. 


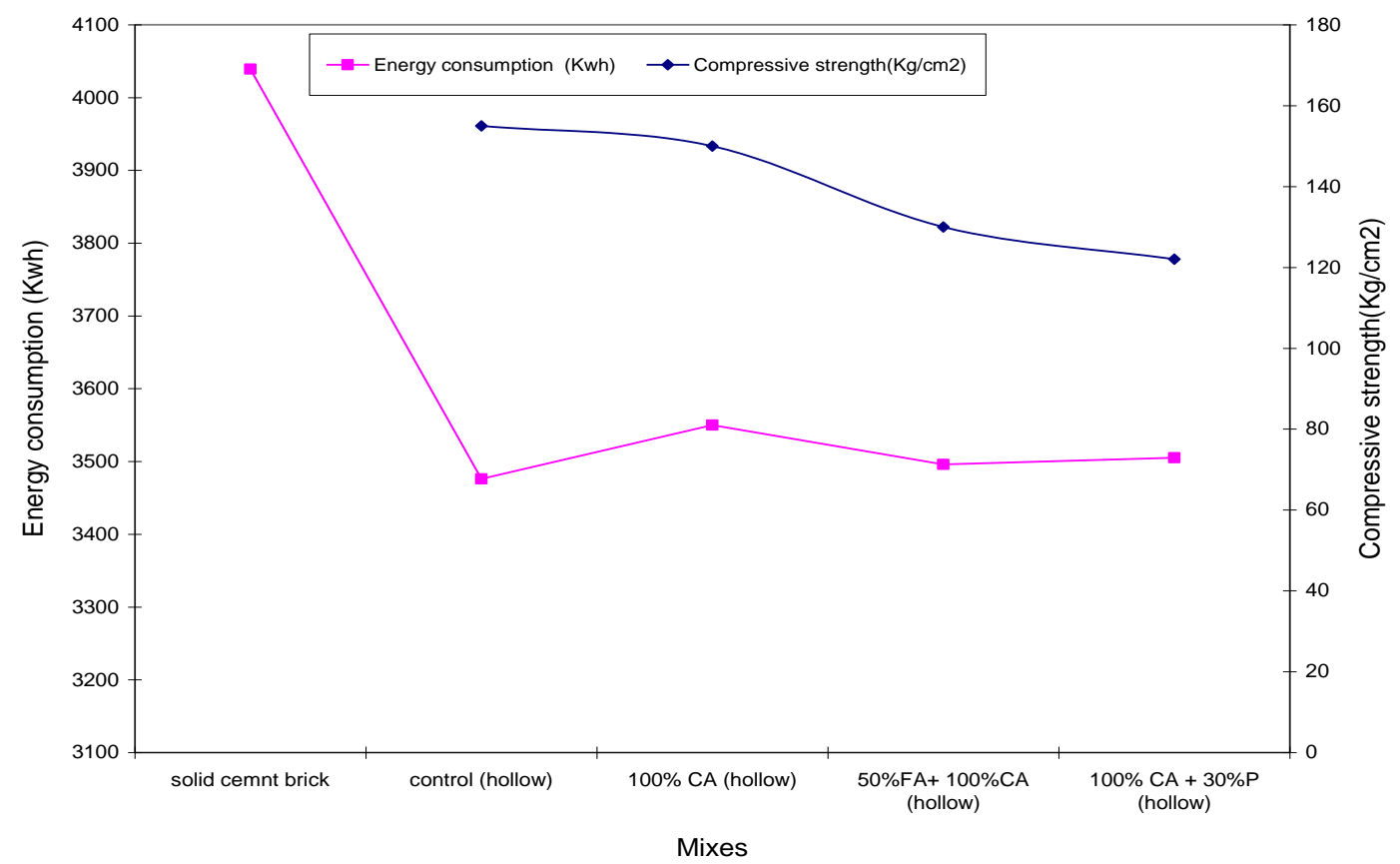

Fig. (13): Effect and comparing between the effects of the different sizes of marble waste on Energy consumption and Compressive strength. Source: researcher

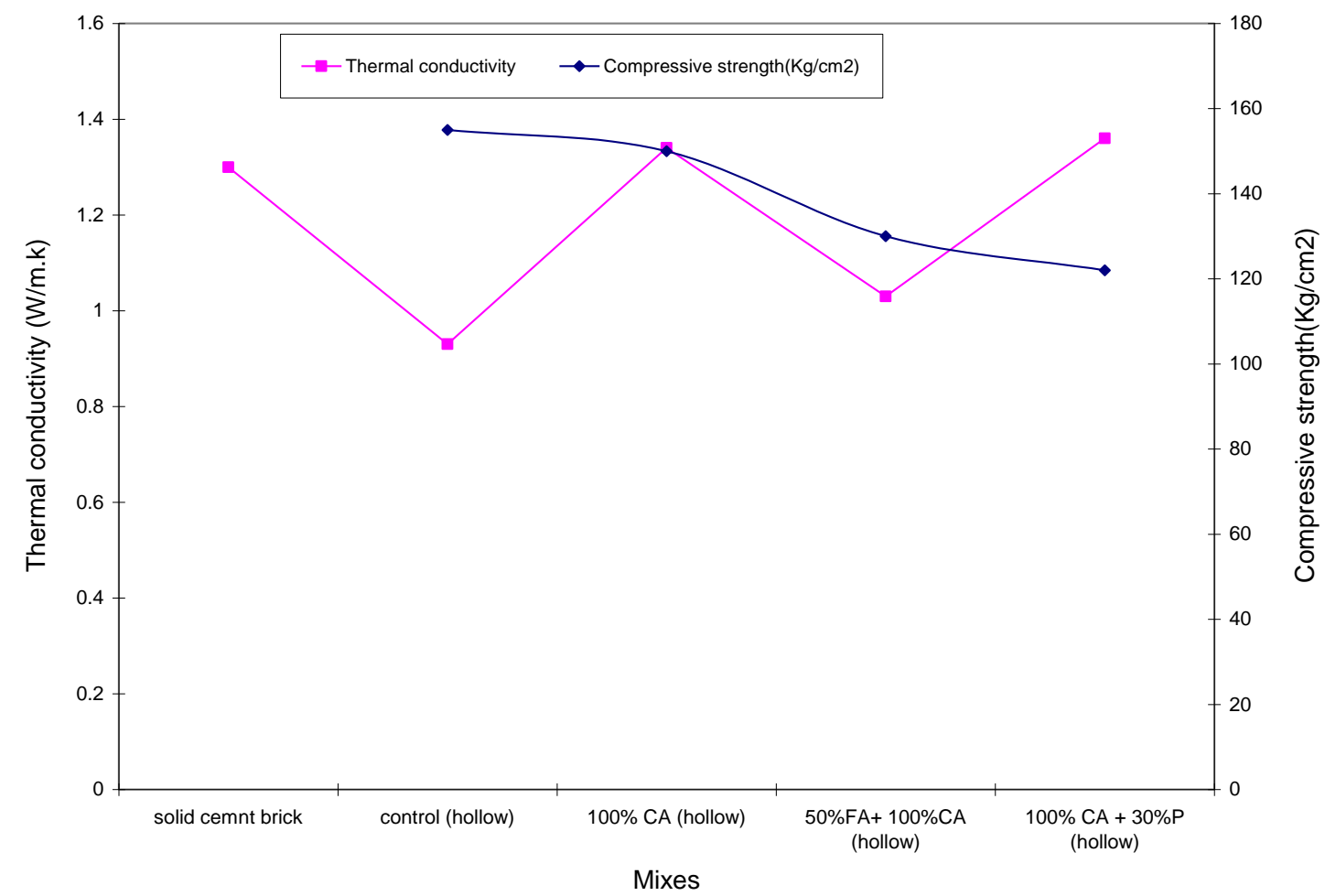

Fig. (14): Effect and comparing between the effects of the different sizes of marble waste on Thermal conductivity and Compressive strength. Source: researcher

\subsection{Total energy savings}


It is important to understand that not all building systems will necessarily achieve simultaneously what may be perceived to be desirable goals. The designer must balance the potentially conflicting goals of:

- Minimizing energy use, including heating and cooling energy as well as the energy used to produce the building materials

- Minimizing cost, including heating and cooling cost as well as the cost associated with particular building-construction practices

Comparing between the effects of the different sizes of marble waste on energy consumption for choose samples.

The effect using different sizes of marble waste on the energy consumption for control hollow concrete blocks in building. For mixes were compared with the control solid concrete bricks made with conventional materials (cement, dolomite and sand).

It can be found for the figure that the percentage of saving in electricity equal $14 \%$ when using hollow concrete blocks in walls instead of solid concrete brick in wall and in [hollow concrete blocks roofs] instead of [roof reinforced concrete].

The effecting using different sizes of marble waste (100\% CA) on the energy consumption of hollow concrete blocks using in building when using blocks in walls and roof. It can be found for the figure that the percentage of saving in electricity equal $3550 \mathrm{Kwh}$

The effecting using different sizes of marble waste $(50 \% \mathrm{FA}+100 \% \mathrm{CA})$ on the energy consumption of hollow concrete blocks using in building. It can be found for the figure that the percentage of saving in electricity equal $3496 \mathrm{Kwh}$.

The effecting using different sizes of marble waste $(100 \% \mathrm{CA}+30 \% \mathrm{MP})$ on the energy consumption of hollow concrete blocks using in building. It can be found for the figure that the percentage of saving in electricity equal $3505 \mathrm{Kwh}$.

\section{Economic study}

The results in this study showed that the marble wastes mixtures can be used to produce hollow load bearing concrete blocks, while $(50 \% \mathrm{FA}+100 \% \mathrm{CA})$ and $(100 \% \mathrm{CA}+30 \% \mathrm{MP})$ marble wastes mixtures can be used to produce hollow non-load bearing concrete blocks at 28 days. Economically, According to table(6), (7) the cost estimate materials and marble waste ratios could reduce between $22.33 \%$ and $27.54 \%$ per 1000 ,block for hollow non-load bearing concrete block production for mixtures $(50 \% \mathrm{FA}+100 \% \mathrm{CA})$ and $(100 \% \mathrm{CA}+$ $30 \% \mathrm{MP}$ ), respectively. For the hollow load bearing concrete block production, mixture (100\% CA) can reduce the cost at $19.36 \%$ per 1000 , block.

Table (7) Prices average for materials is used in study

\begin{tabular}{|l|l|l|} 
Materials and commodities & Unity & average price (pounds)
\end{tabular}




\begin{tabular}{|c|c|c|}
\hline Price of cement & Ton & 900 \\
\hline Price of sand & cubic meter & 80 \\
\hline Price of coarse aggregates & cubic meter & 160 \\
\hline Price of marble fragments & Ton & zero \\
\hline Price of marble powder & Ton & zero \\
\hline Price of fine marble waste & Ton & 45 \\
\hline Price of coarse marble waste & Ton & 90 \\
\hline Price of water & cubic meter & 3 \\
\hline Electricity (pounds /block) & Hour & 60 \\
\hline
\end{tabular}

\section{Conclusions}

- The physical and mechanical properties of cement composites were affected by using marble sludge: water absorption and apparent porosity increased with increasing marble content, while the density and compressive strength decreased.

- The compressive strength of hollow concrete block is decreased with addition of waste marble powder up to $30 \%$ replace by weight of cement.

- Using of fine marble waste ratio in mixture to make a hollow non-load bearing concrete block.

- The generality test results revealed that the coarse aggregate of the recycled waste materials (marble wastes) can be utilized in hollow concrete blocks mixture as reasonable substitute of natural dolomite.

- Using of coarse marble waste ratio in mixture to make a hollow load bearing concrete block.

- Using the environmental pollutants in serving the environment to maintain the general health of the citizen and improve economics of the industry, have put forth a simple step to minimize the costs for construction with usage of marble wastes which is freely or cheaply available.

- Production of various mixed ratio of hollow concrete blocks from marble waste used as a fine aggregate and coarse aggregate and powder, could be a profitable disposal alternative in the future and will be of the highest value possible for the foreseeable future.

- The addition of marble wastes has negligible effect on the mechanical properties during the entire process, anticipating no costly modifications in the industrial production line.

- Implementing sustainability in the element of waste management consider sustainable waste management sequence to lessen waste generation

- Economic and social environment and applying all sustainable architecture strategies.

- Thermal insulation property of hollow concrete block is suitable due to presence of air in hollow concrete units.

- Uses the marble wastes to make hollow concrete blocks will influence on the thermal conductivity negative. 


\section{References}

1. Hamza, R. A., El-Haggar, and Khedr ,S.(2011) Marble and Granite Waste: Characterization and Utilization in Concrete Bricks. International Journal of Bioscience, Biochemistry and Bioinformatics:Vol. 1(4)

2. Corinaldesi, V., Moriconi, G., \& Naik, T. (2010). Charactarization of Marble Powder for its Use in Mortar Concrete. Construction and Building Materials, 24, 113-117. [On-line]. ScienceDirect.

3. Rodrigues, R., de Brito, J., Sardinha, M., (2015). Mechanical properties of structural concrete containing veryfine aggregates from marble cutting sludge. Constr. Build. Mater. 77, 349e356.

4. Ergun, A., (2011). Effects of the usage of diatomite and waste marble powder as partial replacement of cement on the mechanical properties of concrete. Constr. Build. Mater. 25, 806e812.ESS. No. 1109, 2002.

5. Rana, A., Kalla, P., Csetenyi, L.J., (2015). Sustainable use of marble slurry in concrete. J. Clean. Prod. 94, 304e311.

6. Aliabdo, A.A., Abd Elmoaty, M.A., Auda, E.M., (2014). Re-use of waste marble dust in the production of cement and concrete. Constr. Build. Mater. 50,28e41.

7. Ahmed O. Mashaly, Baher A. El-Kaliouby, Basel N. Shalaby, Amr M. El eGohary, Mohammed A. Rashwan, (2016) Effects of marble sludge incorporation on the properties of cement composites and concrete paving blocks, Journal of Cleaner Production 112, 731e741

8. Gencel, O., Ozel, C., Koksal, F., Erdogmus, E., Martínez-Barrera, G., Brostow, W., (2012). Properties of concrete paving blocks made with waste marble. J. Clean. Prod. 21, 62e70.

9. Dhanapandian, S. and Gnanavel, B. (2009). Studies on granite and marble sawing powder wastes in industrial brick formulations. Asian Journal of Applied Sciences. 2 (4) : 331-40.

10. N. Bilgin, H.A. Yeprem, S. Arslan, A. Bilgin, E. Günay, M. Mars_oglu (2012) " Use of waste marble powder in brick industry" Construction and Building Materials. 29 449-457.

11. Klrglz, M. S. (2007). The usage of the wastes of marble and brick industries in cement manufacturing as mineralogical additive, $\mathrm{PhD}$ Thesis, Ankara: Gazi University Graduate School of Natural and Applied Sciences. (https://tez.yok.gov.tr/UlusalTezMerkezi/(for reading abstract of thesis, please write full name of author known Mehmet Serkan KIRGIZ to search engine above webpage then click "Bul"button).

12. Y.H. Ye, W.M. Sun, et al(2005), Experimental Study on hollow block masonry walls filled with foaming concrete, 10th Canadian Masonry Symposium, Banff, Alberta, June 8 - 12,

13. Koski, J.A., 1992. How Concrete Block are Made. Masonry Construction, pp: $374-377$.

14. S. O. Adepo , K. A. Imoukhuede, S. S. James, Experimental analysis of heat conduction through hollow building blocks, International Journal of 
Engineering Technologies and Management Research, 5(5), 179-183. DOI: $10.5281 /$ zenodo. 1296942.

15. Navaratnarajah, Sathiparan \& K. N. Anusari, M \& N. Samindika, N. (2014). Effect of Void Area on Hollow Cement Masonry Mechanical Performance. Arabian Journal for Science and Engineering. 39. 75697576.

16. Egyptian Standard Specifications. Load bearing concrete masonry units, (2005). Rep. No. 1292-1.

17. Egyptian Standard Specifications. No-load bearing concrete masonry units, (2005). Rep. No. 1292-2.

18. Standard Test Methods for Sampling and Testing Concrete Masonry Units and Related Units, Copyright ASTM International Provided by IHS under license with ASTM C140 - 11a, Current edition approved Aug. 1, 2011. Published September 2011. Originally approved in 1938. Last previous edition approved in (2011) as C140 - 11. DOI: 10.1520/C0140-11A.

19. Design Builder. Available online: http://www.designbuilder.co.uk (accessed on 10 January 2013).

20. EN ISO 6946: (1996)Building Components and Building ElementsThermal Resistance and Thermal Transmittance - Calculation Method; European Committee for Standardization: Brussels, Belgium.

21. Bonavetti, V., Donza, H., Rahhal, V., Irassar, E., (2000). Influence of initial curing on the properties of concrete containing limestone blended cement. Cem. Concr. Res.30, 703e708.

22. Güneyisi, E., Geso glu, M.,€Ozbay, E., (2009). Effects of marble powder and slag on the properties of self-compacting mortars. Mater. Struct. 42, 813e826

23. Heikal, M., El-Didamony, H., Morsy, M.S., (2002). Limestonefilled pozzolanic cement.Cem. Concr. Res. 30, 1827e1834.

24. Meddah, M.S., Lmbachiya, M.C., Dhir, R.K., (2014). Potential use of binary and com-posite limestone cements in concrete production. Constr. Build. Mater. 58,193e205.

25. Rana, A., Kalla, P., Csetenyi, L.J., (2015). Sustainable use of marble slurry in concrete. J. Clean. Prod. 94, 304e311. 